\title{
Satellite DNA as a target for TaqMan real-time PCR detection of the pinewood nematode, Bursaphelenchus xylophilus
}

\author{
CECILE FRANÇOIS ${ }^{1}$, CHANTAL CASTAGNONE¹, NEIL BOONHAM², JENNY TOMLINSON², \\ REBECCA LAWSON², SUE HOCKLAND², JAMES QUILL², PAULO VIEIRA ${ }^{3}$, MANUEL MOTA ${ }^{3}$ AND \\ PHILIPPE CASTAGNONE-SERENO ${ }^{1, *}$ \\ 'INRA, UMR1064 Interactions Plantes-Microorganismes et Santé Végétale, 400 route des Chappes, BP167, F-06903 Sophia Antipolis, France \\ ${ }^{2}$ Central Science Laboratory, Sand Hutton, York Y041 1LZ, UK \\ ${ }^{3}$ Department of Biology, University of Evora, P-7002554, Evora, Portugal
}

\section{SUMMARY}

The pinewood nematode (PWN), Bursaphelenchus xylophilus, is a major pathogen of conifers, which impacts on forest health, natural ecosystem stability and international trade. As a consequence, it has been listed as a quarantine organism in Europe. A real-time PCR approach based on TaqMan chemistry was developed to detect this organism. Specific probe and primers were designed based on the sequence of the Mspl satellite DNA family previously characterized in the genome of the nematode. The method proved to be specific in tests with target DNA from PWN isolates from worldwide origin. From a practical point of view, detection limit was $1 \mathrm{pg}$ of target DNA or one individual nematode. In addition, PWN genomic DNA or single individuals were positively detected in mixed samples in which $B$.xylophilius was associated with the closely related non-pathogenic species $B$. mucronatus, up to the limit of $0.01 \%$ or $1 \%$ of the mixture, respectively. The real-time PCR assay was also used in conjunction with a simple DNA extraction method to detect PWN directly in artificially infested wood samples. These results demonstrate the potential of this assay to provide rapid, accurate and sensitive molecular identification of the PWN in relation to pest risk assessment in the field and quarantine regulation.

\section{INTRODUCTION}

Pine wilt is a major disease of pine (Pinus spp.) forests caused by the pinewood nematode (PWN), Bursaphelenchus xylophilus. The PWN is indigenous to North America where it is not considered as a pathogen on native pine species. However, the nematode

*Correspondence: Tel.: +33 492386439; Fax: +33 492386587;

E-mail: Philippe.Castagnone@sophia.inra.fr constitutes a severe pest in countries where it has been introduced. For example, about $30 \%$ of the total area of pine forest is estimated to be infested by this species in Japan (Mamiya, 2004), following its introduction via the timber trade. Owing to the potential threat to forest ecosystems, regulations have been introduced in many countries to prevent introduction and/or further spread of $B$. xylophilus. In Europe, the recent discovery of the PWN in a restricted area in Portugal (Mota et al., 1999) has led to its listing as a quarantine pest, and to the implementation of national large-scale surveys to monitor the pathogen and special phytosanitary measures for conifer wood packaging materials imported from areas where the nematode has been recorded (EU directive 2000/29/EC). To be effective, such regulation steps strongly depend on accurate detection of the pathogen.

More than 70 species of Bursaphelenchus are currently recognized, and their morphological identification requires a high level of expertise (Ryss et al., 2005). In particular, species belonging to the 'pinewood nematode species complex', such as B. xylophilus and B. mucronatus, share several morphological characteristics, and may even be subject to reciprocal genetic exchange through hybridization (De Guiran and Bruguier, 1989). In recent years, conventional PCR based on direct visualization of amplicons (Castagnone et al., 2005; Kang et al., 2004; Matsunaga and Togashi, 2004; Takeuchi et al., 2005) or RFLP analysis of amplicons (Burgermeister et al., 2005) have provided useful methods for identification of the PWN. However, the multistep process of amplicon analysis, involving gel electrophoresis, and the risk of post-PCR contamination mean that conventional PCR protocols are not appropriate for high-throughput routine testing. To overcome such limitations, real-time PCR coupled to automated product analysis appears to be a promising alternative, as postPCR handling for target detection is no longer required. Instead, fluorescent monitoring of amplicon accumulation allows target detection, based on the cycle threshold $(\mathrm{Ct})$ value, i.e. the number of PCR cycles at which the amplicon product curve exceeds fluorescence background (Heid et al., 1996). Applicability of this 


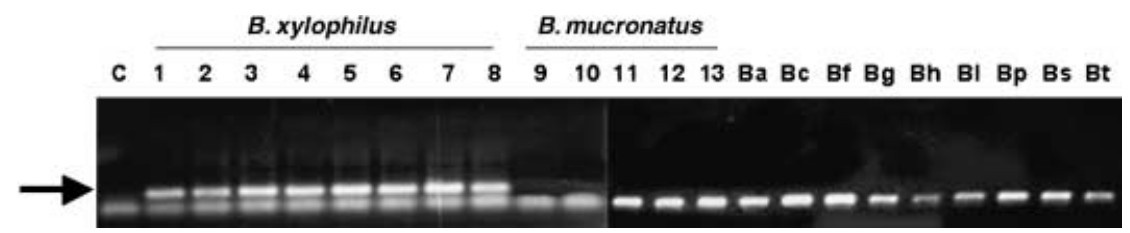

Fig. 1 Specific amplification of Bursaphelenchus xylophilus satellite DNA using primers BsatF and BsatRV in conventional PCR. The arrow indicates the specific fragment amplified in B. xylophilus isolates only. Assays were performed using $10 \mathrm{ng}$ of genomic DNA template. In the negative control, DNA was replaced by water. The order of the lanes in the gel is the same as for the Bursaphelenchus spp. isolates listed in Table 3.

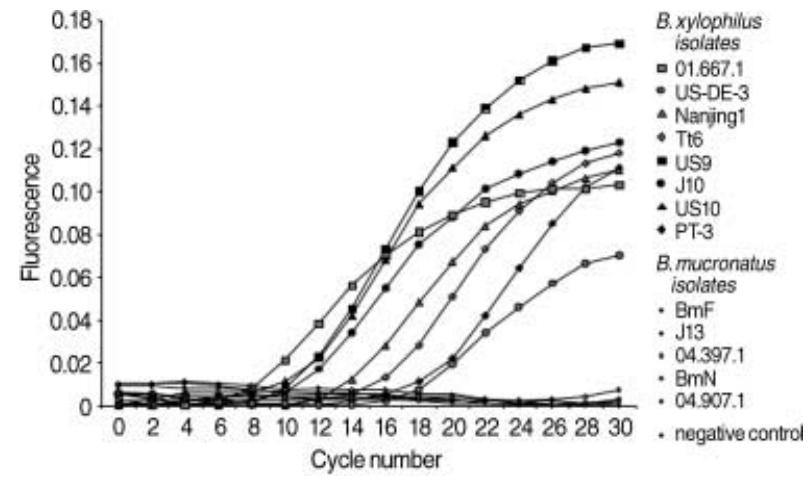

Fig. 2 Specificity of the TaqMan real-time PCR assay for Bursaphelenchus xylophilus. Assays were performed using $10 \mathrm{ng}$ of genomic DNA template from the B. xylophilus and B. mucronatus isolates listed in Table 3. In the negative control, DNA was replaced by water. To avoid overlapping and confusing symbols, the same symbol $(\bigcirc)$ was used for all the $B$. mucronatus isolates.

new technology to the detection of plant-parasitic nematodes has very recently been tested (Holeva et al., 2006; Madani et al., 2005), including the PWN (Cao et al., 2005), using ribosomal DNA as a target sequence.

The aim of this study was the development and evaluation of a real-time PCR assay for routine sample screening to detect the PWN, based on the specific Mspl satellite DNA family previously cloned in the genome of the parasite (Tarès et al., 1993). To improve the accuracy of real-time PCR, TaqMan chemistry has been incorporated into our assay. This chemistry combines the use of a target-specific oligonucleotide probe dual-labelled with a donor fluorophore and an acceptor dye, and the 5 '-exonuclease activity of Taq polymerase (Holland et al., 1991), thus combining the sensitivity of PCR and the specificity of DNA hybridization.

\section{RESULTS}

\section{Specificity and sensitivity of TaqMan real-time PCR assays}

In a previous study, we showed that the Mspl satellite DNA repetitive unit was not detected by conventional PCR in the genome of three congeneric species, i.e. B. mucronatus, B. tusciae

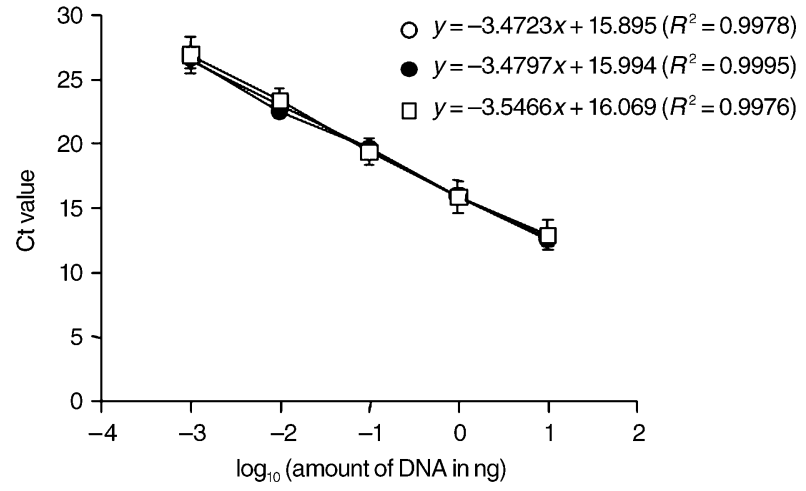

Fig. 3 Standard curves showing Ct values plotted against the $\log _{10}$ of known amounts of Bursaphelenchus xylophilus genomic DNA in three independant experiments (average of five replicates $\pm S D$ ). Nematode genomic DNA was serially diluted to yield final amounts ranging from $10 \mathrm{ng}$ to $1 \mathrm{pg}$. For each experiment, the regression line equation and its $R^{2}$ value are displayed.

and B. leoni (Castagnone et al., 2005). Here, in conventional $P C R$, the BSatF and BSatRV primers amplified a fragment of the expected size (approximately $80 \mathrm{bp}$ ) from all the B. xylophilus isolates but did not amplify from isolates belonging to the ten other Bursaphelenchus species tested nor from the negative control (Fig. 1). In TaqMan real-time PCR optimized assays, genomic DNA from the B.xylophilus isolates was specifically amplified, while fluorescence remained below the threshold values for the negative control and the isolates of the non-target species $B$. mucronatus (Fig. 2). Some variation in $\mathrm{Ct}$ values was observed between $B$. xylophilus isolates, which suggested variation between isolates in the genomic content of the Mspl satDNA family.

The sensitivity of the nematode TaqMan PCR assays was measured with ten-fold dilution series of purified genomic DNA. Bursaphelenchus xylophilus target DNA was detectable in samples containing as little as 1 pg DNA (Fig. 3). Standard curves showed a negative linear correlation between $\mathrm{Ct}$ values and the $\log _{10}$ of the known amount of DNA over a range of $10 \mathrm{ng}$ to $1 \mathrm{pg}$ (Fig. 3). The same result was confirmed in three separate experiments using different dilution series, which illustrates the sensitivity and linearity of the detection within a wide range of input template DNA amount (Fig. 3). 


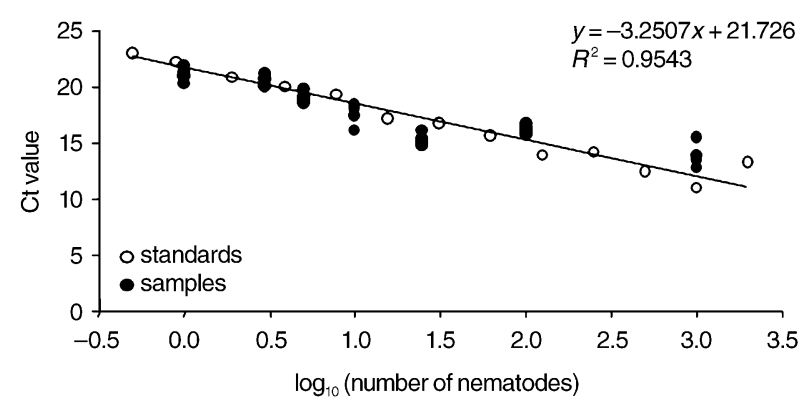

Fig. 4 Real-time PCR testing of batches of individual Bursaphelenchus xylophilus, showing the correlation between $\mathrm{Ct}$ values and numbers of nematodes, in comparison with a standard curve constructed using serial dilutions of a DNA extract prepared from 2000 nematodes. For the standard curve, the regression line and its $R^{2}$ value are displayed.

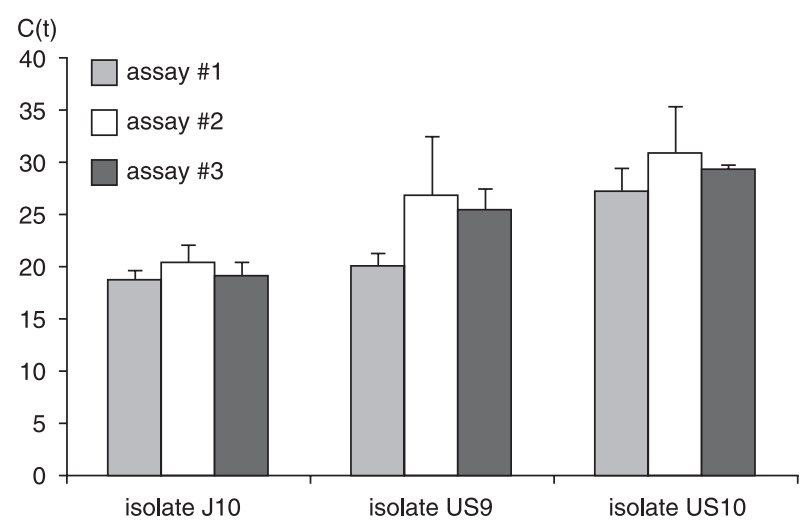

Fig. 5 Comparison of real-time PCR testing of individual nematodes of three different Bursaphelenchus xylophilus isolates as performed in three independent assays (average of five replicates \pm SD).

\section{Application of TaqMan assays to individual nematodes}

Detection of the target DNA from batches of individual B. xylophilus nematodes was performed by comparison of the $\mathrm{Ct}$ values of the samples to those obtained from the standard dilutions of DNA prepared from 2000 nematodes, using in both cases the simplified DNA extraction method. Samples consisted of DNA extracted from batches of 1-1000 individual nematodes, and the corresponding average $\mathrm{Ct}$ values ranged from approximately 22 to 15 , in good correlation with the standard curve (Fig. 4). In particular, detection of single nematodes was always efficient, which confirms the sensitivity of the detection. In addition, if we compare the average $\mathrm{Ct}$ value for one nematode to the results of the dilution assays with genomic DNA (Fig. 3), we can extrapolate that the analytical sensitivity of the real-time $P C R$ assay with genomic DNA is approximately equivalent to $1 / 25$ nematode per reaction. Very similar results were obtained with
Table 1 Real-time PCR (TaqMan) detection of Bursaphelenchus xylophilus in mixed samples. Ct values are means \pm SD.

\begin{tabular}{|c|c|c|c|c|}
\hline & \multicolumn{2}{|c|}{$\begin{array}{l}\text { Composition of } \\
\text { the samples }\end{array}$} & \multirow{2}{*}{$\begin{array}{l}\text { Percentage } \\
\text { B. xylophilus } \\
\text { in the samples }\end{array}$} & \multirow[b]{2}{*}{$\mathrm{Ct}$} \\
\hline & B. xylophilus & B. mucronatus & & \\
\hline \multirow{3}{*}{$\begin{array}{l}\text { DNA } \\
\text { samples }\end{array}$} & $10 \mathrm{pg}$ & $1 \mathrm{ng}$ & $1 \%$ & $24.85 \pm 0.74$ \\
\hline & $10 \mathrm{pg}$ & $10 \mathrm{ng}$ & $0.1 \%$ & $24.25 \pm 0.61$ \\
\hline & $10 \mathrm{pg}$ & $100 \mathrm{ng}$ & $0.01 \%$ & $24.91 \pm 0.82$ \\
\hline \multirow{4}{*}{$\begin{array}{l}\text { Nematode } \\
\text { samples }\end{array}$} & 1 nematode & 1 nematode & $50 \%$ & $25.58 \pm 2.35$ \\
\hline & 1 nematode & 4 nematodes & $20 \%$ & $23.47 \pm 1.84$ \\
\hline & 1 nematode & 19 nematodes & $5 \%$ & $22.64 \pm 0.66$ \\
\hline & 1 nematode & 99 nematodes & $1 \%$ & $23.55 \pm 1.96$ \\
\hline
\end{tabular}

different $B$. xylophilus isolates, and showed reproducible results between independent assays (Fig. 5).

\section{Application of TaqMan assays to mixed samples}

In order to evaluate the TaqMan assay in conditions closer to real quarantine determination, we tested the specific detection of the target in mixed samples. In a first step, samples consisted of mixtures of genomic DNA from both B. xylophilus $(10 \mathrm{pg})$ and B. mucronatus (varying amounts from $1 \mathrm{ng}$ to $100 \mathrm{ng}$ ). B. xylophilus DNA was unambiguously detected when present from $1 \%$ to $0.01 \%$ in the mixed sample (Table 1). In our conditions, the dilution level did not affect the sensitivity of the detection (with Ct values ranging from 24.25 to 24.91; Table 1 ). In a second series of experiments, $B$. xylophilus and $B$. mucronatus individual nematodes were mixed in varying proportions, the target species representing from $50 \%$ to $1 \%$ of the sample. Again, one single B. xylophilus was always specifically detected in the different mixtures tested (Table 1).

\section{Detection of PWN in artificially infested wood by real-time $P C R$}

In order further to validate the Mspl satellite DNA family as a target of interest for PWN diagnostics, TaqMan assays were conducted with templates resulting from direct processing of 0.1-g fragments of wood artificially inoculated with the nematode. Indeed, PWN DNA was detected in a variety of PWN-infested wood samples, either trunk pieces or smaller branches (Table 2). In each sample, the number of nematodes was estimated after extraction in Baermann funnel, and ranged from ten to 138 nematodes (Table 2). For the trunk samples, PWN DNA was amplified in undiluted extracts, while it was necessary to dilute the small branch extracts 1:10 to get amplification, suggesting a certain amount of PCR inhibitors were carried over in these extracts. No fluorescence was detected for the negative controls tested (non-inoculated wood samples). 
Table 2 Real-time PCR (TaqMan) detection of Bursaphelenchus xylophilus in wood, and nematode isolation results for replicate samples. Samples of $0.2 \mathrm{~g}$ of infested wood were cut into small pieces, then divided in half. DNA was extracted from one half of the sample $(0.1 \mathrm{~g})$, and nematodes were isolated from the other half, and the numbers of adults and juveniles were recorded. $\mathrm{Ct}$ values are means \pm SD

\begin{tabular}{lll}
\hline Sample & Nematodes isolated & $\mathrm{Ct}$ \\
\hline Trunk 1.5-2 cm diameter & 70 adults, 68 juveniles & $16.82 \pm 0.06^{*}$ \\
Trunk 1.5-2 cm diameter & 7 adults, 3 juveniles & $22.49 \pm 0.10^{*}$ \\
Small branches $<5$ mm diameter & 10 adults, 8 juveniles & $25.76 \pm 0.08+$ \\
\hline
\end{tabular}

*Extracts tested without dilution.

tExtract diluted $1: 10$.

\section{DISCUSSION}

A real-time PCR assay, using TaqMan chemistry, has been developed for the specific detection of the PWN, a quarantine organism in Europe. Compared with conventional PCR assays, one major advantage of real-time $P C R$, in the particular context of diagnostics, is its wide detection range due to the determination of the $\mathrm{Ct}$ values at an early stage of the reaction. Furthermore, no time-consuming post-PCR detection of amplification products by gel electrophoresis is required. Within the real-time PCR assay, the use of the TaqMan chemistry gives a better specificity to the detection compared with non-specific DNA binding dyes (e.g. SYBR Green), for which detection may be disturbed by nonspecific product formation (Mackay et al., 2002; Schena et al., 2006).

The specific distribution of satellite DNA observed here in B. xylophilus has been documented in many organisms, including entomopathogenic and plant parasitic nematodes (reviewed in Grenier et al., 1997), and could be linked to some structural role of these sequences, i.e. chromosome folding. In particular, due to its close association with centromeric histones, it has been proposed that satellite DNA may be driving adaptive evolution of these proteins, leading in this way to the speciation process via a loss of compatibility between chromosomes in hybrids (Henikoff et al., 2001). Moreover, such repetitive sequences evolve by means of concerted evolution, resulting ultimately in homogenization of changes among repeats within the genome and their subsequent fixation in members of reproductively isolated populations (i.e. biological species) in a process known as molecular drive (Dover, 1986).

In a recent report, Cao et al. (2005) described a TaqMan procedure that could be used to detect as little as $0.01 \mathrm{ng}$ of B. xylophilus DNA, using the nematode ribosomal DNA internal transcribed region as a target. The assay described here appears ten-fold more sensitive, with a reproducible detection limit of $1 \mathrm{pg}$ of genomic DNA. The higher sensitivity of the technique is due, at least in part, to the presence of a large number of monomers of the Mspl satellite in each cell of the PWN. Indeed, this repetitive family was estimated to constitute up to $30 \%$ of the genome of the nematode (Tarès et al., 1993). Taking into account the genome size, estimated to be about $30 \times 10^{6} \mathrm{bp}$ for the closely related species $B$. mucronatus (Leroy et al., 2003), this indicates an approximate copy number of $56 \times 10^{3}$ per haploid genome. Comparatively, the number of copies of the rDNA cistron ranges between 50 and 100 in the PWN genome, as deduced from the number in the genome of the model nematode Caenorhabditis elegans (Sulston and Brenner, 1974). This magnitude clearly indicates that satellite DNA is a very suitable target for diagnostics, as recently exemplified with real-time PCR detection of the protozoan parasite Trypanosoma brucei (Becker et al., 2004).

Our results showed some variability in Ct values among B. xylophilus isolates, which can be interpreted as a variation between isolates in the genomic content of the Mspl satellite DNA family. Although proportionality was achieved, for any tested isolate, between genomic DNA concentration or number of nematodes and fluorescence detection, this observation precludes the use of the Mspl repetitive family as a target region for quantitative analysis of unknown isolates. Nevertheless, because of the evolutionary patterns of satellite DNAs, such variation is not unexpected. Indeed, with respect to copy number, satellite DNAs can vary dramatically in their content among related organisms, and it has been proposed that extensive amplifications and deletions could act as a driving force in the evolution of these sequences (Ugarkovic and Plohl, 2002). Such variations in copy number have been exemplified previously in both plant- and animal-related genomes (e.g. Alix et al., 1998; Pons et al., 2002). However, in spite of such variation, the Mspl target sequence was always found as highly reiterated in all the B. xylophilus isolates tested, which constitutes, along with its species-specific distribution, a major advantage of satellite DNA as a target for detection purpose.

In wood samples, the PWN is often associated with the closely related non-pathogenic species $B$. mucronatus, which constitutes the most prevalent Bursaphelenchus species found in European coniferous forests (Braasch, 2001; L. Robertson, pers. com.). In this context, detection of the PWN in samples containing both species appears essential for diagnostic purposes. The procedure presented here meets such a requirement, as B.xylophilus genomic DNA or single individuals were positively detected in mixed samples, up to the limit of $0.01 \%$ or $1 \%$ of the mixture, respectively. From that point of view, it should be considered as a candidate methodology for diagnosing PWN infection in epidemiological surveys as well as in regulatory testing.

The presence in wood of substances that strongly inhibit PCR is a frequent problem for PCR-based systems used to detect plant pathogens in woody hosts (Langrell and Barbara, 2001). Despite the development of widely applicable plant DNA extraction 
procedures designed to minimize co-extraction of inhibitory compounds, inhibition remains a major impediment to many routine applications, compromising both assay sensitivity and reliability (Bickley and Hopkins, 1999). In particular, polysaccharides and secondary plant metabolites (such as polyphenols and phenolic compounds) are common, PCR-inhibitory contaminants of DNA extracts made from wood samples. The method described here for DNA extraction from infested wood uses minimal disruption of the sample, such that PWN DNA can be detected but inhibitors in the wood, which could prevent amplification, are not released. However, dilution was needed to get positive amplification in the case of small branches, which indicated that substances inhibiting PCR were nevertheless present in such samples. Despite this, the ability of the real-time PCR assay to detect less than one genome equivalent per reaction allows extracts to be diluted without the risk of false negative results. Modifications to this method to standardize the protocol, increase throughtput, increase the size of samples that can be processed and improve sampling could increase the advantages of routine direct testing of wood samples. Clearly, the need for such a test is especially pressing in light of the recent discovery of B. xylophilus in Europe (Mota et al., 1999), and the increasing impact of this invasive pest on international trade regulation.

\section{EXPERIMENTAL PROCEDURES}

\section{Biological materials}

The Bursaphelenchus isolates used in this study, with their original host and geographical origin, when available, are listed in Table 3. Isolates were cultured monoxenically on the fungus Botrytis cinerea in a Petri dish on potato dextrose agar medium at $25^{\circ} \mathrm{C}$.

To test the detection of the nematode without prior isolation, wood samples were artificially inoculated as follows. Three-year seedlings of Pinus pinaster were inoculated at the base with c. 3000 nematodes of the B. xylophilus PT-3 isolate. Six weeks after inoculation (i.e. seedlings showing wilting symptoms extending over $50 \%$ of current-year needles), all the needles were removed, and the trunk was separated from the branches. From each edge of the trunk, several discs (3-mm thickness) were cut to constitute the tested wood samples. To check the success of infestation, the nematodes were extracted from $0.1-\mathrm{g}$ wood samples using the Baermann funnel technique for $48 \mathrm{~h}$ (Mamiya, 1975).

\section{DNA extraction from nematodes}

Genomic DNA was purified from pooled nematodes of each isolate using the phenol/chloroform method (Sambrook et al., 1989), quantified spectrophotometrically and aliquoted and
Table 3 Isolates of the Bursaphelenchus species tested.

\begin{tabular}{llll}
\hline Nematode species & Isolate & Host & Origin \\
\hline B. xylophilus & J10 & Pinus densiflora & Japan \\
B. xylophilus & US9 & P. halepensis & USA \\
B. xylophilus & US10 & Abies balsamea & USA \\
B. xylophilus & 01.667 .1 & packaging wood & Canada \\
B. xylophilus & PT-3 & P. pinaster & Portugal \\
B. xylophilus & Nanjing 1 & P. thumbergii & China \\
B. xylophilus & Tt 6 & ? & Japan \\
B. xylophilus & US-DE-3 & P. taeda & USA \\
B. xylophilus & J13 & P. thumbergii & Japan \\
B. xylophilus & BmF & P. pinaster & France \\
B. xylophilus & BmN & P. sylvestris & Norway \\
B. xylophilus & 03.397 .1 & P. nigra & France \\
B. xylophilus & 04.907 .1 & P. pinaster & France \\
B. antoniae & Leiria & Hylobius sp. & Portugal \\
B. conicaudatus & BcoJ & Ficus carica & Japan \\
B. fraudulentus & BFHU & Quercus robus & Hungary \\
B. hofmanni & AT5W & P. sylvestris & Austria \\
B. glochis & $03-814-1$ & P. sylvestris & France \\
B. luxuriosae & BluJ & Acalolepta luxuriosa & Japan \\
B. pinophilus & 04-841-1 & P. sylvestris & France \\
B. sexdentati & Guadalupe & P. pinaster & Portugal \\
B. tusciae & IT-14w & P. pinea & Italy \\
\hline & & & \\
\hline
\end{tabular}

stored at $-80^{\circ} \mathrm{C}$. Alternatively, DNA from a defined number of nematodes (1-2000 individuals) was extracted using a simplified procedure, as previously described (Castagnone et al., 2005), with a slight modification. Unlike the original protocol, the volume of lysis buffer used was not constant but adapted to the number of nematodes, i.e. $3 \mu \mathrm{L}$ for $1-4$ nematodes and $20 \mu \mathrm{L}$ for higher numbers of nematodes.

\section{DNA extraction from PWN-infested wood samples}

DNA extraction from infested wood was performed using a ChargeSwitch gDNA Plant kit from Invitrogen (Carlsbad, CA). Approximately $0.1 \mathrm{~g}$ of infested wood was cut into small pieces and placed into a plastic bag with $5 \mathrm{~mL}$ of CST lysis buffer containing $1 \%$ polyvinylpyrrolidone and $20 \mathrm{~mm}$ calcium chloride. The sample was lightly disrupted using a hammer, then $1 \mathrm{~mL}$ of lysate was removed and processed according to the manufacturer's instructions. Briefly, $100 \mu \mathrm{L}$ sodium dodecyl sulphate was added to the lysate and incubated at room temperature for $5 \mathrm{~min}$, then $400 \mu \mathrm{L}$ precipitation buffer was added and centrifuged at maximum speed (approximately $18000 \mathrm{~g}$ ) for $5 \mathrm{~min}$. Approximately $1 \mathrm{~mL}$ of supernatent was removed, and $100 \mu \mathrm{L}$ of CST detergent and $40 \mu \mathrm{L}$ CST beads were added. A PickPen 8-M from Bio-Nobile (Turku, Finland) was used to transfer the CST beads and bound DNA through two washing steps (1 $\mathrm{mL}$ CST Wash Buffer) and into $150 \mu \mathrm{L}$ CST Elution Buffer in a 2.2-mL deep well plate, followed by removal of the Magnetic Particles. The DNA 
was either tested immediately or stored at $-20{ }^{\circ} \mathrm{C}$ for future analysis.

\section{Primers and TaqMan probe design}

Real-time PCR primers BSatF (5'-TGACGGAGTGAATTGACAAGACA-3') and BSatRV (5'-AAGCTGAAACTTGCCATGCTAAA-3') were designed to amplify a 77-bp-long amplicon of the target sequence from B.xylophilus Mspl satDNA monomeric unit (accession number L09652). The fluorogenic TaqMan probe BSatS (5'-ACACCATTCGAAAGCTAATCGCCTGAGA-3') was designed to anneal to a 30-bp region located between the primer pair. A BLAST search was performed on the amplicon sequence to ensure specificity. The probe was labelled at the $5^{\prime}$ end with 6 carboxyfluorescein (FAM) as reporter dye, and modified at the 3 ' end with the quencher dye tetra-methylcarboxyrhodamine (TAMRA). Primers and probe were synthesized by Eurogentec (Belgium).

\section{Amplification conditions}

Optimal conditions were determined by performing real-time PCR assays with concentration gradients of primers (50-900 nM) and probe (50-250 nм) at different annealing and extension temperatures $\left(58-65^{\circ} \mathrm{C}\right)$. Conditions were considered as optimal if they produced the lowest $\mathrm{Ct}$ values and the highest fluorescence. By definition, $\mathrm{Ct}$ represents the number of amplification cycles at which the detected fluorescence exceeds the fluorescence background (Heid et al., 1996). In our experimental conditions, the fluorescence of the negative controls used never exceeded such background, and thus no $\mathrm{Ct}$ values could be attributed to these negative controls.

Real-time PCR reactions were performed in a total volume of $25 \mu \mathrm{L}$ in $0.2 \mathrm{~mL}$ Low Profile tube strips (ABgene, UK) containing $1 \mu \mathrm{L}$ of genomic DNA. Each reaction contained $2.5 \mu \mathrm{L}$ of $10 \times$ reaction buffer (qPCR Core Kit, Eurogentec, Belgium), $5 \mathrm{~mm} \mathrm{MgCl}$, $200 \mu \mathrm{m}$ each dNTPs, 0.5 unit Taq polymerase (qPCR Core Kit) and $200 \mathrm{~nm}$ each primer and probe. Thermal cycling conditions consisted of $10 \mathrm{~min}$ at $95^{\circ} \mathrm{C}$, followed by 30 cycles of $15 \mathrm{~s}$ at $95^{\circ} \mathrm{C}$ and $30 \mathrm{~s}$ at $59^{\circ} \mathrm{C}$.

Real-time PCR assays on nematode and nematode DNA samples were performed in a DNA Engine Opticon 2 (MJ Research). Data were analysed using the Opticon 2 Monitor software version 3.1 according to the manufacturer's instructions. The $\mathrm{Ct}$ values for each reaction were calculated automatically by the software by determining the PCR cycle number at which the reporter fluorescence exceeded background. Triplicate reactions were performed in each assay, and each assay was repeated at least three times.

Real-time PCR testing of wood extracts was performed on a SmartCycler II (Cepheid, Sunnyvale, CA). Each reaction consisted of $0.025 \mathrm{U} / \mu \mathrm{L}$ Hot Taq (Biogene, Kimbolton, UK), $1 \times$ PCR buffer, $0.2 \mathrm{~mm}$ each dNTP, $5.5 \mathrm{~mm} \mathrm{MgCl}, 5 \%$ trehalose (w/v), $300 \mathrm{~nm}$ each primer and $100 \mathrm{~nm}$ probe. Cycling conditions were $10 \mathrm{~min}$ at $95^{\circ} \mathrm{C}$ followed by 40 two-step cycles of $15 \mathrm{~s}$ at $95^{\circ} \mathrm{C}$ and $1 \mathrm{~min}$ at $60^{\circ} \mathrm{C}$. Data were analysed using the default threshold setting of the SmartCycler software (30 fluorescence units). Extracts were tested undiluted and diluted $1: 10$ in nuclease-free water.

Conventional PCR reactions were performed as described above using Eurogentec qPCR Core Kit reagents, except that no probe was added to the reactions. Amplicons were analysed by electrophoresis in $2 \%$ agarose gels containing ethidium bromide in TBE buffer (Sambrook et al., 1989), and visualized under UV light.

\section{ACKNOWLEDGEMENTS}

This work was funded by the European Union (contract Portcheck SSPE-CT-2004-502348). We thank Drs G. Anthoine and T. Schroëder for providing nematode isolates, Dr P. Bonants for helpful discussion, and two anonymous reviewers for helpful comments on the manuscript.

\section{REFERENCES}

Alix, K., Baurens, F.C., Paulet, F., Glaszmann, J.C. and D'Hont, A. (1998) Isolation and characterization of a satellite DNA family in the Saccharum complex. Genome, 41, 854-864.

Becker, S., Franco, J.R., Simarro, P.P., Stich, A., Abel, P.M. and Steverding, D. (2004) Real-time PCR for detection of Trypanosoma brucei in human blood samples. Diagn. Microbiol. Infect. Dis. 50, 193-199.

Bickley, J. and Hopkins, D. (1999) Inhibitors and enhancers of PCR. In: Analytical Molecular Biology Quality and Validation (Suppl. 190) (Saunders, G.C. and Parkes, H.C., eds), pp. 81-102. Wiltshire, UK: Redwood Books Ltd.

Braasch, H. (2001) Bursaphelenchus species in conifers in Europe: distribution and morphological relationships. EPPO Bull. 31, 127-142.

Burgermeister, W., Metge, K., Braasch, H. and Buchbach, E. (2005) ITS-RFLP patterns for differentiation of 26 Bursaphelenchus species (Nematoda: Parasitaphelenchidae) and observations on their distribution. Russ. J. Nematol. 13, 29-42.

Cao, A.X., Liu, X.Z., Zhu, S.F. and Lu, B.S. (2005) Detection of the pinewood nematode, Bursaphelenchus xylophilus, using a real-time polymerase chain reaction assay. Phytopathology, 95, 566-571.

Castagnone, C., Abad, P. and Castagnone-Sereno, P. (2005) Satellite DNA-based species-specific identification of single individuals of the pinewood nematode Bursaphelenchus xylophilus (Nematoda: Aphelenchoididae). Eur. J. Plant Pathol. 112, 191-193.

De Guiran, G. and Bruguier, N. (1989) Hybridization and phylogeny of the pine wood nematode (Bursaphelenchus spp.). Nematologica, 35, 321330.

Dover, G.A. (1986) Molecular drive in multigene families: how biological novelties arise, spread and are assimilated. Trends Genet. 2, 159-165.

Grenier, E., Castagnone-Sereno, P. and Abad, P. (1997) Satellite DNA sequences as taxonomic markers in nematodes of agronomical interest. Parasitol. Today, 13, 398-400. 
Heid, C.A., Stevens, J., Livack, K.J. and Williams, P.M. (1996) Real time quantitative PCR. Genome Res. 6, 986-994.

Henikoff, S., Ahmad, K. and Malik, H.S. (2001) The centromere paradox: stable inheritance with rapidly evolving DNA. Science, 293, 10981102.

Holeva, R., Phillips, M.S., Neilson, R., Brown, D.J.F., Young, V., Boutsika, K. and Blok, V.C. (2006) Real-time PCR detection and quantification of vector trichodorid nematodes and Tobacco Rattle Virus. Mol. Cel. Probes, 20, 203-211.

Holland, P., Abramson, R.D., Watson, R. and Gelfand, D.H. (1991) Detection of specific polymerase chain reaction product by utilizing the 5'-3' exonuclease activity of Thermus aquaticus DNA polymerase. Proc. Natl Acad. Sci. USA, 88, 7276-7280.

Kang, J.S., Choi, K.S., Shin, S.C., Moon, I.S., Lee, S.G. and Lee, S.H. (2004) Development of an efficient PCR-based diagnosis protocol for the identification of the pinewood nematode, Bursaphelenchus xylophilus (Nematoda: Aphelenchoididae). Nematology, 6, 279-285.

Langrell, S.R.H. and Barbara, D.J. (2001) Magnetic capture hybridisation for improved PCR detection of Nectria galligena from lignified apple extracts. Plant Mol. Biol. Reptr. 19, 5-11.

Leroy, S., Duperray, C. and Morand, S. (2003) Flow cytometry for parasite nematode genome size measurement. Mol. Biochem. Parasitol. 128, 9193.

Mackay, I.M., Arden, K.E. and Nitsche, A. (2002) Real-time PCR virology. Nucleic Acids Res. 30, 1292-1305.

Madani, M., Subbotin, S.A. and Moens, M. (2005) Quantitative detection of the potato cyst nematode, Globodera pallida, and the beet cyst nematode, Heterodera schachtii, using real-time PCR with SYBR green I dye. Mol. Cel. Probes, 19, 81-86.

Mamiya, Y. (1975) Efficiency of Baermann funnel method for the extraction of pinewood nematodes. For. Pest, 24, 115-119.

Mamiya, Y. (2004) Pine wilt disease in Japan. In: The Pinewood Nematode,
Bursaphelenchus Xylophilus. Nematology Monographs and Persectives, 1 (Mota, M. and Vieira, P., eds), pp. 9-20. Leiden, The Netherlands: Brill.

Matsunaga, K. and Togashi, K. (2004) A simple method for discriminating Bursaphelenchus xylophilus and B. mucronatus by species-specific polymerase chain reaction primer pairs. Nematology, 6, 273-277.

Mota, M.M., Braasch, H., Bravo, M.A., Penas, A.C., Burgermeister, W., Metge, K. and Sousa, E. (1999) First report of Bursaphelenchus xylophilus in Portugal and in Europe. Nematology, 1, 727-734.

Pons, J., Petitpierre, E. and Juan, C. (2002) Evolutionary dynamics of satellite DNA family PIM357 in species of the genus Pimelia (Tenebrionidae, Coleoptera). Mol. Biol. Evol. 19, 1329-1340.

Ryss, A., Vieira, P., Mota, M. and Kulinich, 0. (2005) A synopsis of the genus Bursaphelenchus Fuchs, 1937 (Aphelenchida: Parasitaphelenchidae) with keys to species. Nematology, 7, 393-458.

Sambrook, J., Fritsch, E.F. and Maniatis, T. (1989) Molecular Cloning: a Laboratory Manual, 2nd edn. Cold Spring Harbor, NY: Cold Spring Harbor Laboratory Press.

Schena, L., Hughes, K.J.D. and Cooke, D.E.L. (2006) Detection and quantification of Phytophthora ramorum, P. kernoviae, P. citricola and $P$. quercina in symptomatic leaves by multiplex real-time PCR. Mol. Plant Pathol. 7, 365-379.

Sulston, J.E. and Brenner, S. (1974) The DNA of Caenorhabditis elegans. Genetics, 77, 95-104.

Takeuchi, Y., Kanzaki, N. and Futai, K. (2005) A nested PCR-based method for detecting the pine wood nematode, Bursaphelenchus xylophilus, from pine wood. Nematology, 7, 775-782.

Tarès, S., Lemontey, J.M., de Guiran, G. and Abad, P. (1993) Cloning and characterization of a highly conserved satellite DNA sequence specific for the phytoparasitic nematode Bursaphelenchus xylophilus. Gene, 129, 269-273.

Ugarkovic, D. and Plohl, M. (2002) Variation in satellite DNA profilescauses and effects. EMBO J. 21, 5955-5959. 